\title{
A New Colorimetric Method for the Estimation of Histidine and Histamine
}

\author{
By P. M. NEWMAN AND J. H. TURNBULL \\ Chemistry Department, University of Birmingham, Edgbaston, Birmingham, 15
}

(Received 24 July 1959)

Histidine occurs widely in nature both in the free and combined form. In order to study histidine in its various roles it is necessary therefore to have a sensitive and specific method for its estimation. The colorimetric method described initially by Pauly (1904) and since modified by various workers (Koessler \& Hanke, 1919; Jorpes, 1932; Macpherson, 1942; Sanger \& Tuppy, 1951), which depends on the reaction of histidine with an aromatic diazonium salt to form a red azo dye, is widely used but suffers from its low specificity. Kapeller-Adler (1933) developed a quantitative colorimetric method based on a reaction discovered by Knoop (1908), which depends on a bromination of histidine in acetic acid. This method, which is specific for histidine and closely related compounds, has not proved entirely satisfactory and many modifications have been suggested (Tsuverkalov \& Torban, 1951; Hunter, 1952, 1955; Voigt, 1959).

We have discovered a reaction of histidine with iodine and pyridine in which a violet colour is developed. This has led to a convenient and reliable method for the estimation of histidine and histamine which may be used for the analysis of solutions containing as little as $1 \mu \mathrm{g} . / \mathrm{ml}$.

\section{EXPERIMENTAL}

Materials. L-Histidine hydrochloride monohydrate was obtained from British Drug Houses Ltd. and was used without further purification. Technical-grade pyridine was fractionally distilled in the presence of phosphorus pentoxide until a fraction of constant boiling point $\left(115^{\circ}\right)$ was obtained. This was stored over solid sodium hydroxide in the dark. A solution of potassium tri-iodide was prepared by dissolving $0.075 \mathrm{~g}$. of AnalaR iodine in $0.4 \mathrm{~g}$. of AnalaR potassium iodide in $10 \mathrm{ml}$. of water. Sodium dithionite was AnalaR grade and a $0.02 \mathrm{M}$ solution was prepared.

Method. The absorption spectra and extinctions of the coloured reaction mixture were determined with a Unicam SP. 500 spectrophotometer (Cambridge Instrument Co.). Introduction of small quantities of reagent to the reaction mixture was accomplished with the aid of an Agla micrometer syringe (Burroughs Wellcome and Co.) fitted with a long delivery capillary.

The method of colour production used in the experiments described in this paper was as follows. A solution of no more than $3 \mathrm{ml}$. volume containing $1-35 \times 10^{-2} \mu$ moles (1-55 $\mu$ g.) of histidine was pipetted into a $5 \mathrm{ml}$. graduated flask. From a burette, $1.2 \mathrm{ml}$. of pyridine was added and the solution was adjusted to $\mathrm{pH} 11 \cdot 0-12.0$ with $0.2 \mathrm{~N}$ sodium hydroxide. The bulk of the solution was made up to approx. $4.5 \mathrm{ml}$. with water. The micrometer syringe was used to introduce $0.04 \mathrm{ml}$. of the potassium tri-iodide reagent. The flask was immediately shaken until the contents were homogeneous and the violet was allowed to develop at room temperature for exactly 30 sec., timing being commenced from the moment the reagent had been added. At the end of this period, further colour formation was checked by the addition of $0.5 \mathrm{ml}$. of $0.02 \mathrm{~N}$-sodium dithionite and the solution was mixed until homogeneous. The volume was adjusted to exactly $5 \mathrm{ml}$. with water, and, after standing for $\mathbf{5} \mathrm{min}$., the solution was transferred to a silica spectrophotometer cell of $1 \mathrm{~cm}$. cross-section. The extinction of the solution was measured at a wavelength of $560 \mathrm{~m} \mu$ within $15 \mathrm{~min}$. of development, against a blank containing all the reagents.

\section{RESULTS}

Factors controlling development of colour. In early experiments the reagent used was methylpyridinium iodide hexaiodide dissolved in pyridine, prepared by the method of Trowbridge \& Diehl (1897). This compound appears to dissociate in pyridine solution with the formation of both $\mathrm{Py}^{+} \mathrm{I}$ and $\mathrm{I}_{3}{ }^{-}$ions, as shown from spectrographic evidence (Reid \& Mulliken, 1954). Later experiments indicated that a solution of elementary iodine in pyridine was more convenient. Unfortunately solutions of iodine in pyridine are rather unstable (Zingaro, VanderWerf \& Kleinberg, 1951), and refinement of the method led to the use of potassium tri-iodide in water as a stable reagent. Experiments with various solutions of potassium iodide and iodine proved that maximum colour development was possible if the reagent was prepared by dissolving $0.075 \mathrm{~g}$. of iodine and $0.4 \mathrm{~g}$. of potassium iodide in $10 \mathrm{ml}$. of water. Excessive quantities of iodide were to be avoided as this led to a diminution of colour intensity. This, however, and the effect of other anions will be discussed later.

Erratic results were obtained when technicalgrade pyridine was used but this was remedied by fractionation to a constant-boiling pyridine. The role of pyridine in the reaction is unknown, but its specificity is quite marked. Other pyridine derivatives were tried but only 2:6-lutidine produced any 
colour, and this was of low intensity. 4-Chloro-, $\alpha$-hydroxy-, $\beta$-hydroxy-, $N$-oxy-pyridines, pyridine carbinol and nicotinamide all gave negative results.

Colour development is also dependent on the $\mathrm{pH}$ of the reaction mixture and thus careful adjustment is necessary for consistent results. Experiment proved that the maximum colour intensity was obtained at $\mathrm{pH} 11 \cdot 0-12 \cdot 0$.

Characteristics and stability of colour. The characteristic violet obtained during the reaction has the absorption spectrum shown in Fig. 1. There is a sharp peak with a maximum absorption at $560 \mathrm{~m} \mu$ and a subsidiary shoulder at $450 \mathrm{~m} \mu$. The former was used for the estimation of histidine. The violet pigment was observed to decompose in the presence of excess of iodine and as this process took place the main peak diminished and the shoulder assumed more importance. When a large excess of iodine was present this process was rapid, the development of the violet being hardly detectable and the absorption of the reaction mixture showing no peak at $560 \mathrm{~m} \mu$. The colour of this solution was orange-brown.

This phenomenon made quantitative application of the reaction difficult as it was often necessary to add fairly large excesses of iodine to solutions of low histidine content to obtain a calibration curve of useful range. This difficulty was overcome by the introduction of a technique whereby all excess of iodine was removed from the system as soon as development of the violet was complete. Sodium dithionite proved to be a suitable reagent for the purpose and a calculated quantity was therefore added to the reaction mixture as the colour approached its maximum intensity. An arbitrary time of $30 \mathrm{sec}$. was chosen as the period in which

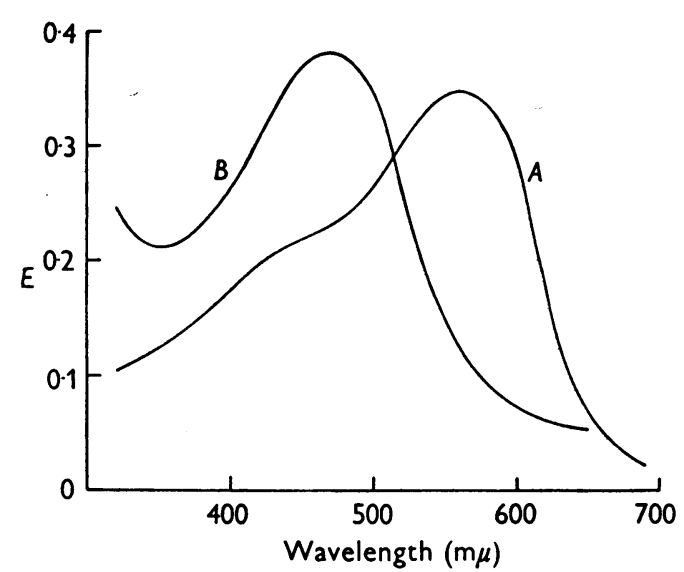

Fig. 1. Ultraviolet-absorption spectra of the final reaction mixture, prepared as described in the text, containing $25 \mu \mathrm{g}$. of histidine: $(A)$ normal reaction mixture at $\mathrm{pH} 11 \cdot 0-12 \cdot 0 ;(B)$ reaction mixture after addition of excess of $0.01 \mathrm{~N}-\mathrm{HCl}(\mathrm{pH} \mathrm{9 \cdot 0-9 \cdot 5)}$. the colour was allowed to develop, as this gave good colour intensities without appreciable interference from the brown decomposition product. A further advantage of this technique was that it rendered the blank solution completely transparent at $560 \mathrm{~m} \mu$, and thus possible errors introduced from this source were eliminated. The dithionite, in addition, may protect the pigment from oxidation as its presence considerably increased the colour stability. Even with the use of dithionite, the colour was observed to fade slowly in the dark, though reliable measurements of colour intensity could be made within $15 \mathrm{~min}$. of development of the colour.

Specificity and interference. The ability to form the violet colour with pyridine and iodine appears to be confined to compounds very closely related to histidine. Histidine, histamine and histidine methyl ester are the only compounds so far investigated which exhibit this colour reaction readily. $N$-Acetylhistidine, imidazole and carnosine ( $N$ - $\beta$-alanylhistidine) gave negative results, whereas histidine amide produced only a very faint colour, which may merely be due to hydrolysis to free histidine under the alkaline conditions of the reaction. The following compounds gave no detectable violet colour under the specified conditions: benzimidazole, tryptophan, $N$-acetyltryptophan, indoleacetic acid, creatinine, $\beta$-alanine, $\beta$ phenylalanine, tyrosine, sarcosine, $\beta$-mercaptoethylamine, ascorbic acid, 3-amino-1:2:4-triazole and xanthine.

It would appear therefore that the violet is formed only by compounds possessing the $\beta$ aminoethyl-4 (or -5)-imidazole structure, with or without an $\alpha$-carboxylic substituent. Fig. 2 shows the effect of modifying the carboxyl group of

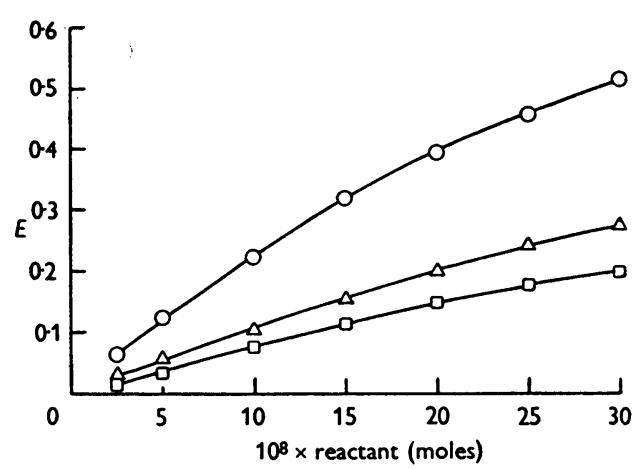

Fig. 2. Calibration curves for the spectrophotometric estimation of histidine $(O)$, histamine $(\triangle)$ and histidine methyl ester ( $\square$ ). Solutions were prepared as described in the text and $0.04 \mathrm{ml}$. of potassium tri-iodide reagent was used in all cases. Extinctions were measured at. $560 \mathrm{~m} \mu$. 
histidine. Calibration curves for the estimation of histidine, histamine and histidine methyl ester were plotted, and from these it may be seen that the dependence of colour intensity on structure follows the order:

$$
\mathrm{R} \cdot \mathrm{CO}_{2} \mathrm{H} \gg \mathrm{RH}>\mathrm{R} \cdot \mathrm{CO}_{2} \cdot \mathrm{Me} \gg \mathrm{R} \cdot \mathrm{CO} \cdot \mathrm{NH}_{2},
$$

where $\mathrm{R}$ is $\left(\mathrm{C}_{3} \mathrm{H}_{3} \mathrm{~N}_{2}\right) \mathrm{CH}_{2} \cdot \mathrm{CH}\left(\mathrm{NH}_{2}\right)$. A free $\alpha$-amino group appears to be necessary for colour production.

The amino acids tryptophan and tyrosine normally interfere seriously in colorimetric estimations of histidine. These amino acids, at concentrations approaching $30 \mu \mathrm{g} . / \mathrm{ml}$., themselves produced no detectable colour on treatment with the iodinepyridine reagent, but the presence of either reduced the intensity of the violet formed by histidine. For the microdetermination of histidine and histamine in protein hydrolysates and biological materials it was necessary to remove all interfering substances. This was conveniently achieved by selective absorption of histidine and histamine from samples, by the ion-exchange-resin technique of Voigt (1959). Small amounts of lysine and arginine, which were also absorbed, did not interfere with the estimation. Prior removal of protein by ultrafiltration was found advisable, however.

Heavy metals and some anions were observed to have pronounced effects on colour production. The heavy metals such as copper, zinc and iron probably reduced the availability of free histidine by complex formation (Martell \& Calvin, 1952). Copper, in addition, reacts with pyridine, producing a blue complex which makes estimation of the violet difficult. The influence of various anions is summarized in Fig. 3, which indicates that strong nucleophilic anions, e.g. $\mathrm{SCN}^{-}$, are most effective in reducing colour intensity. In the experiments relating to Fig. 3, $0.05 \mathrm{ml}$. of $0.2 \mathrm{~N}-$ sodium hydroxide was used for $\mathrm{pH}$ adjustment in all cases. It must be borne in mind therefore that the true effect of some of these anions may be complicated by slight $\mathrm{pH}$ differences.

Calibration and reproducibility. Calibration curves for the determination of histidine with various quantities of the potassium tri-iodide reagent are shown in Fig. 4. It was observed that an increase in the quantity of reagent increased the intensity of colour produced. The optimum quantity was found to be $0.04 \mathrm{ml}$., as this gave good intensities in the range $1-60 \mu \mathrm{g}$. (1.5$40 \times 10^{-2} \mu$ moles) of histidine with minimum interference from the brown decomposition product. It is recommended, however, that over the range $20-40 \times 10^{-2} \mu$ moles of histidine, $0.05 \mathrm{ml}$. of reagent should be used for greater accuracy. Histidine and histamine may therefore be detected in solutions containing as little as $1 \mu \mathrm{g} . / \mathrm{ml}$. and determinations may be made with solutions containing more than $2 \mu \mathrm{g} . / \mathrm{ml}$. Reproducibility under these conditions was good, extinction measurements being consistent within $3 \%$. Following the standard practice of duplicate determination on a given solution, we were able to determine the histidine content within $5 \%$.

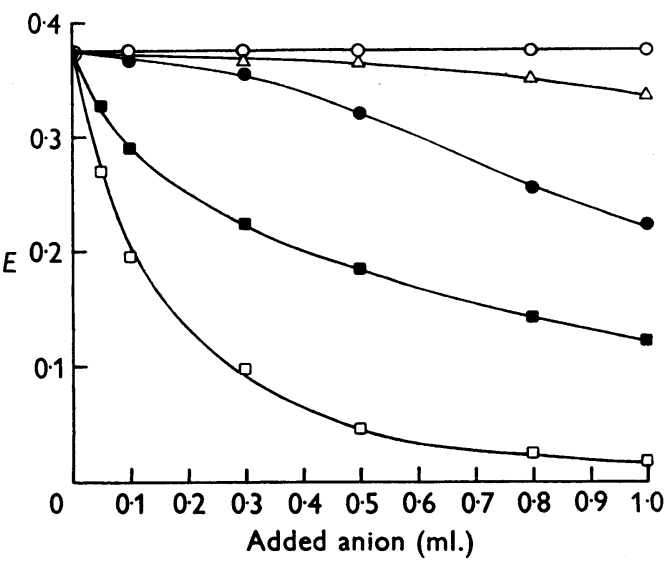

Fig. 3. Effect of various anions on the intensity of colour produced by $30 \mu \mathrm{g}$. of histidine. Solutions were prepared by the standard method except that the stipulated quantity of anion solution was added immediately before the addition of pyridine. $O, 0.1 \mathrm{~m}$-Sodium citrate; $\triangle, 0 \cdot 1 \mathrm{M}$-sodium acetate;, $0 \cdot 1 \mathrm{M}$-sodium iodide; $\square, 0 \cdot 1 \mathrm{~m}$ azide; $\square, 0 \cdot 1 \mathrm{M}$-potassium thiocyanate.

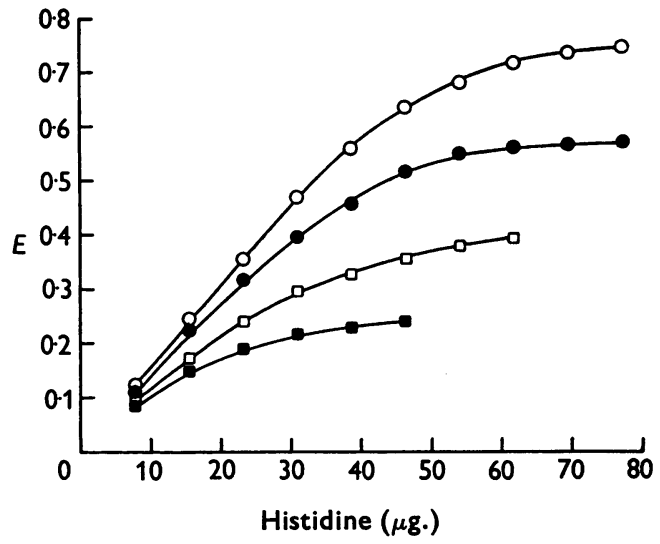

Fig. 4. Calibration curves for the spectrophotometric estimation of histidine with various quantities of potassium tri-iodide reagent. The solutions were prepared as described in the text. Extinctions were measured at $560 \mathrm{~m} \mu$; $\bigcirc$, with $0.05 \mathrm{ml}$. of reagent; , with $0.04 \mathrm{ml}$. of reagent; $\square$, with $0.03 \mathrm{ml}$. of reagent; a, with $0.02 \mathrm{ml}$. of reagent. 


\section{DISCUSSION}

The nature of the violet pigment formed during the reaction is not known. Attempts to isolate the pigment by chromatography and solvent extraction were unsuccessful. It was observed, however, that on addition of mineral acid the violet reaction mixture became orange and this process was reversible. This colour change occurred at $\mathrm{pH} 9 \cdot 5-$ 10.1, which may be taken to indicate that the violet product is anionic in nature, possibly involving a keto-enol system.

The foregoing method was developed with the object of estimating combined histidine in the intact protein molecule. With this in view, the proteins chymotrypsin, trypsin, lysozyme, globin, ribonuclease and glucagon were tested, but no colours were obtained. It is particularly surprising that glucagon yielded negative results, as this protein possesses, in its $N$-terminal histidine (Bromer, Sinn, Staub \& Behrens, 1956), the structural features apparently requisite for colour production.

\section{SUMMARY}

1. A new colorimetric method for the determination of histidine and histamine is described. The method is of use for solutions containing $1-60 \mu \mathrm{g}$. $\mathrm{ml}$.

2. The colour reaction is specific for histidine and closely related compounds, namely, histamine and histidine methyl ester. Imidazole does not react and histidine amide gives only a very faint colour.
3. Tryptophan and tyrosine do not form colours under the conditions of the reaction but interfere with histidine colour formation. The interference of some heavy metals and anions is discussed.

The authors would like to express their thanks to Dr O. K. Behrens for a gift of glucagon. Thanks are also due to Dr C. R. Ricketts, of Birmingham Accident Hospital, for gifts of sera and for helpful discussion.

\section{REFERENCES}

Bromer, W. W., Sinn, L. G., Staub, A. \& Behrens, O. K. (1956). J. Amer. chem. Soc. 78, 3858.

Hunter, A. (1952). J. biol. Chem. 196, 589.

Hunter, A. (1955). J. biol. Chem. 216, 391.

Jorpes, E. (1932). Biochem. J. 26, 1507.

Kapeller-Adler, R. (1933). Biochem. Z. 264, 133.

Knoop, F. (1908). Beitr. chem. Physiol. Path. 11, 356.

Koessler, K. K. \& Hanke, M. T. (1919). J. biol. Chem. 39, 497.

Macpherson, H. T. (1942). Biochem. J. 36, 59.

Martell, A. E. \& Calvin, M. (1952). In The Chemistry of the Metal Chelate Compounds, p. 352. New York: PrenticeHall.

Pauly, H. (1904). Hoppe-Seyl. Z. 40, 565.

Reid, C. \& Mulliken, R. S. (1954). J. Amer. chem. Soc. 76, 3869.

Sanger, F. \& Tuppy, H. (1951). Biochem. J. 49, 1507.

Trowbridge, P. F. \& Diehl, O. C. (1897). J. Amer. chem. Soc. $19,588$.

Tsuverkalov, D. A. \& Torban, M. A. (1951). Biokhimiya, 16, 74. Quoted in Chem. Abstr. (1951). 45, 5223.

Voigt, K. (1959). Biochem. Z. 331, 127.

Zingaro, R. A., VanderWerf, C. A. \& Kleinberg, J. (1951). J. Amer. chem. Soc. 73, 88.

\title{
Isolation and Structure of a New Factor of the Vitamin $B_{12}$ Group: Guanosine Diphosphate Factor B
}

\author{
By R. BARCHIELLI, G. BORETTI, A. DI MARCO, P. JULITA, \\ A. MIGLIACCI, A. MINGHETTI AND C. SPALLA \\ Laboratori Ricerche Farmitalia, Milano, Italia
}

(Received 12 November 1958)

The chromatographic and electrophoretic analysis of the substances having vitamin $\mathrm{B}_{12}$-like activity produced by a strain of Nocardia rugosa (Di Marco \& Spalla, 1957), and by some mutant strains, indicated the presence of vitamin $B_{12}$, factor $B$, and two unknown factors (Di Marco, Alberti, Boretti, Ghione, Migliacci \& Spalla, 1957). These two last substances, which we named factors 1 and 2 , show a growth-promoting activity only for Escherichia coli 113/3 among the vitamin $B_{12}$ requiring micro-organisms tested, and are charac- terized by slow mobility in butanol-acetic acidwater $\left(R_{F}\right.$ values $/ R_{F}$ of vitamin $\mathrm{B}_{12}, 0.12$ and 0.3 respectively) (Fig. 1). Factor 1 is electronegative at $\mathrm{pH}$ values of 2.7 (Fig. 1) and 6.5. The similarity of the chromatographic and electrophoretic behaviour of these substances to that of factors $C_{1}$ and $\mathrm{C}_{2}$ described by Ford \& Porter (1952), Ford, Holdsworth \& Kon (1955) and Dellweg, Becher \& Bernhauer (1956a) prompted us to attempt the isolation and identification of our factors 1 and 2. 